\title{
Cataract in Seckel Syndrome
}

\author{
Vinita Girish Rao, ${ }^{1}$ Gunjan Abhijit Deshpande, ${ }^{1}$ Girish Shiva Rao, ${ }^{1}$ Pooja G Rehman ${ }^{2}$ \\ ${ }^{1}$ Shri Ganapati Netralaya, Jalna, and ${ }^{2}$ Geetanjali Medical College, Udaipur, India
}

\begin{abstract}
Seckel syndrome is an extremely rare inherited disorder characterised by severe growth retardation in utero, which continues later in life, resulting in short stature. Seckel syndrome presents as microcephaly, mental retardation, and a beak-like nose. This report describes a patient with Seckel syndrome who had bilateral cataract and underwent uneventful small incision cataract surgery in both eyes. The association of cataract with Seckel syndrome has not been described in the literature to the best of the authors' knowledge.
\end{abstract}

Key words: Cataract, Dwarfism, Microcephaly, Seckel syndrome 1

Asian J Ophthalmol. 2011;13:12-5.

\section{Introduction}

Seckel syndrome is also known as Seckel dwarfism, bird-headed dwarfism, nanocephalic dwarfism, and microcephalic primordial dwarfism 1 . Seckel syndrome is a very rare disorder, with only a few hundred cases reported in the literature to date. Diagnosed clinically, the condition is characterised by severe prenatal growth retardation, mental deficiency, and characteristic craniofacial abnormalities, including premature synostosis, receding forehead, prominent beak nose, and micrognathia..$^{1,2}$ Inheritance is proposed to be autosomal recessive. ${ }^{3}$ This report presents a patient with cataract associated with Seckel syndrome. To the authors' knowledge, such an association has not been described in the literature before, as evidenced by a MedLine search using the terms: 'Seckel syndrome', 'proportionate dwarfism', 'cataract'.

\section{Case Report}

A 21-year-old woman presented in 2010 with blurring of vision for 6 months. She was the fourth of six siblings born of a consanguineous marriage. She was a full-term baby with a low birth weight. Details of her perinatal history were not available.

At examination, she was affable, cooperative, and followed instructions when prompted. She had been diagnosed to have mental retardation by a physician. Her height was $96 \mathrm{~cm}$ (Figure 1) weight was $25 \mathrm{~kg}$, and head circumference was $40 \mathrm{~cm}$. She had proportionate dwarfism, microcephaly, micrognathia, and a large curved beak-like nose (Figure 2). Her face was symmetrical with a receding forehead. There was absence of clefting and high arched

Correspondence: Dr Gunjan Abhijit Deshpande, 108 B/1 Khare Town, Dharampeth, Nagpur 440010, India.

Tel: (91 712) 253 6589;

E-mail: drgunjandeshpande@gmail.com
Figure 1. Dwarfism in a patient with Seckel syndrome; the patient was $96 \mathrm{~cm}$.

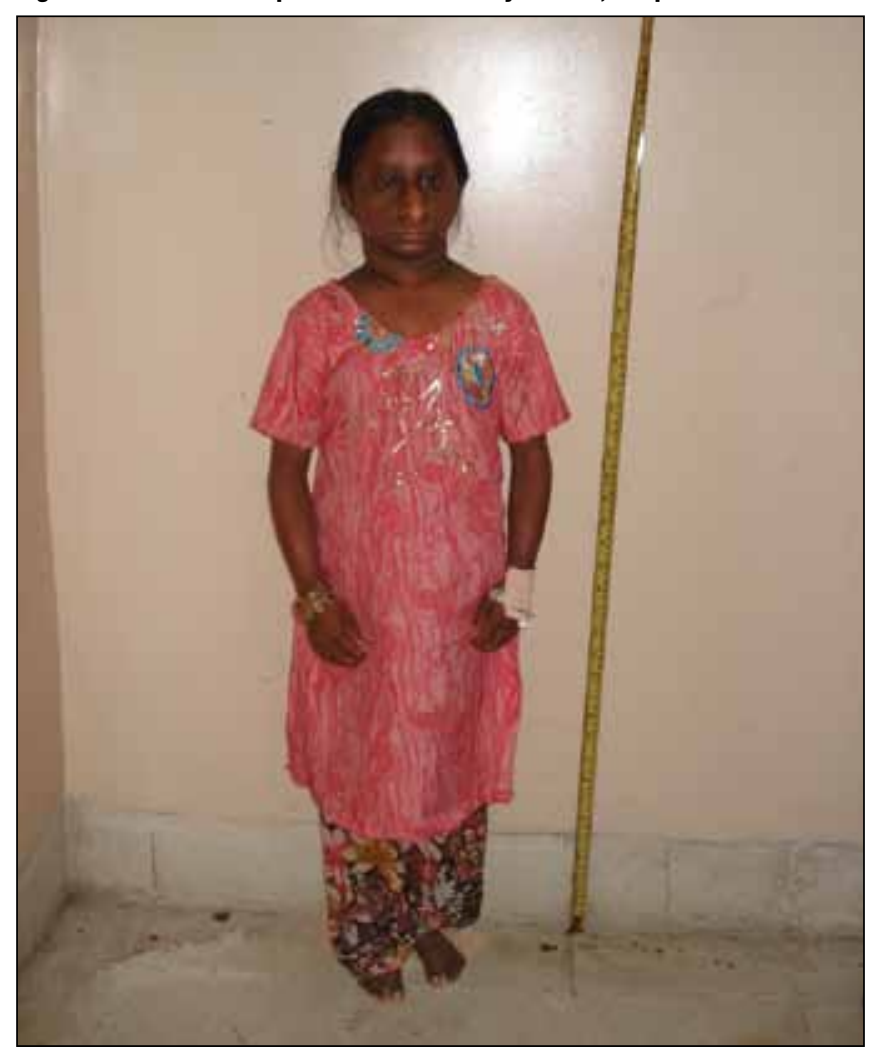

palate. The rest of the facial features were unremarkable, except for webbing of the neck. She had only 3 secondary teeth (2 upper incisors and 1 right upper premolar tooth). No information could be gathered about her primary dentition.

Her hands, fingers, and feet were proportionately small. Limb abnormalities in the form of camptodactyly, pes planus, and short tapering toes with a gap between the first and second toes were present. The rest of the orthopaedic evaluation was within 
Figure 2. Beak-like nose with micrognathia.

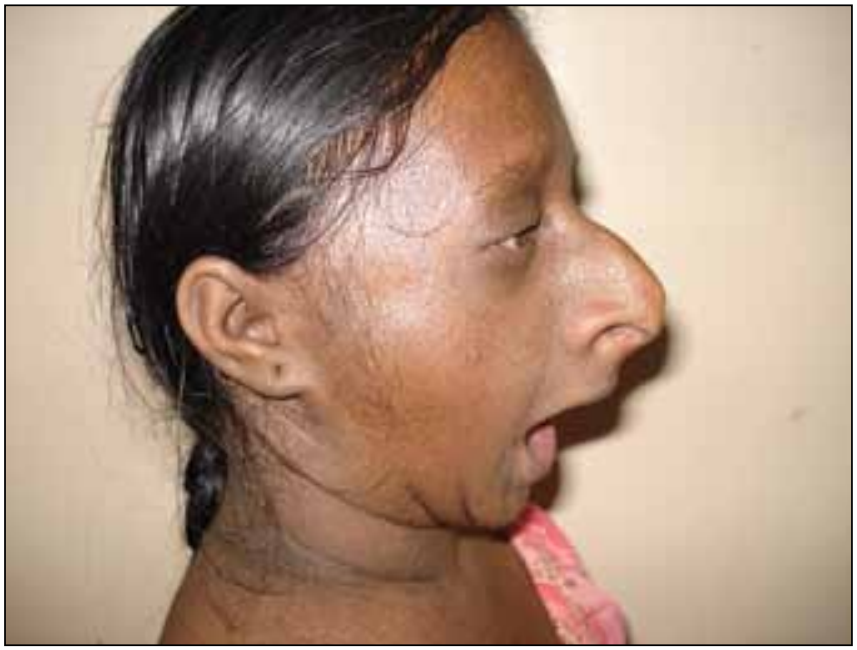

normal limits. Her bone age corresponded to her chronological age. Systemic examination was unremarkable. She had attained menarche with adequate genital development. Her chromosomal karyotype was normal (46XY). Her parents and siblings were healthy with no systemic abnormalities.

Ophthalmic evaluation was remarkable for mature cataract in both eyes. She had telecanthus ( $40 \mathrm{~mm}$ ) and small and downwardslanting palpebral fissures with an interpupillary distance of $22 \mathrm{~mm}$. She had steep corneas (keratometry values: right eye the horizontal meridian was $56.75 \mathrm{D}$ and the vertical meridian was $57.25 \mathrm{D}$; left eye - the horizontal meridian was $55.50 \mathrm{D}$ and the vertical meridian was $57.25 \mathrm{D}$ ) with nanophthalmic axial lengths in both eyes (the right eye was $17.99 \mathrm{~mm}$ and the left eye was $18.02 \mathrm{~mm}$ ). She underwent uneventful small incision cataract surgery with trypan blue with 'in the bag' foldable intraocular lens implantation under local anaesthesia in both eyes (Figure 3). Intraoperatively, apart from the small palpebral fissures posing mechanical difficulty, there were no other problems encountered.

Postoperatively, her vision improved from counting fingers close to the face in both eyes to 20/20 in the right eye and counting fingers at $1 \mathrm{~m}$ in the left eye. Although the disc, macula, and the rest of the fundus examinations of both eyes were within normal limits, the difference in vision between the eyes could not be explained. It was thought that she had had cataract in her left eye since childhood, which resulted in amblyopia.

\section{Discussion}

Seckel described the syndrome in 1960, after studying nanocephalic dwarfs reported in the literature over a 200 -year period. ${ }^{1}$ Seckel described patients with proportionate dwarfism with mental retardation, low birth weight, small head, large eyes, beak-like nose, receding mandible, narrow face, and dental abnormalities.
Figure 3. Intraocular lens reflex in both eyes.

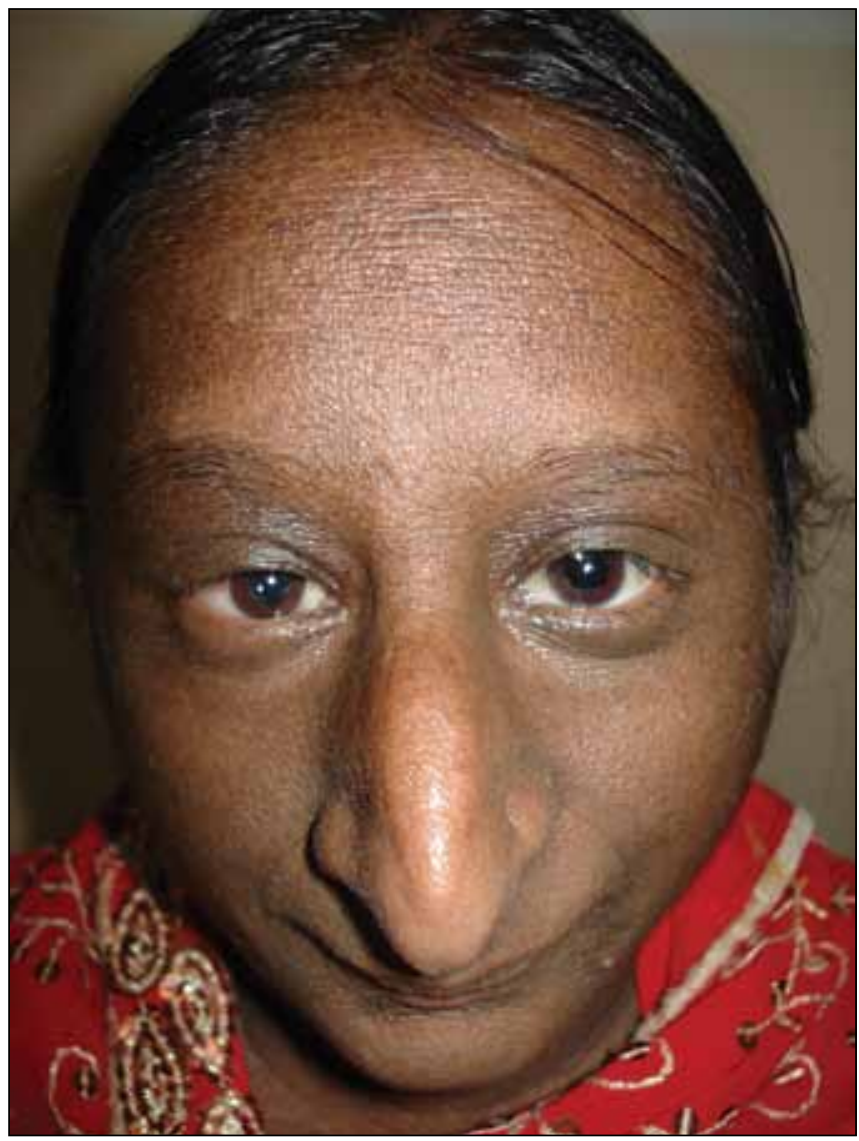

Autosomal recessive inheritance of Seckel syndrome has been reported. $^{3}$

Diagnosis of Seckel syndrome is largely clinical. For this patient, the diagnosis was made by comparing her features with those reported by Majewski and Goecke ${ }^{2}$ and supported by Thompson and Pembrey (Table 1). ${ }^{4}$ Radiological evaluation may be performed for confirming bone deformities. The presence of a parental consanguinous marriage and a history of similar features in her maternal great aunt indicated autosomal recessive inheritance (Figure 4). Chromosomal breakage has been reported in a few cases. In 2000, the gene for Seckel syndrome (SCKL1) was mapped on chromosome 3q22.1-q24 in 2 families and later identified as ataxia-telangiectasia and rad-3-related protein). ${ }^{5}$ Another locus was mapped to chromosome 18p11.31-q11.2 (SCKL2) in 2001 and to chromosome 14q23 (SCKL 3) in $2003 .{ }^{6}$

Systemic associations include Fanconi's anaemia, leukaemia, chronic nephritis, and dysgenesis of the cerebral cortex and corpus callosum. ${ }^{2,7}$ There are a few reports in the literature describing ocular manifestations in the form of telecanthus, small palpebral fissures, large bulging eyes ${ }^{4}$ iris colobomas, ${ }^{6}$ hypotelorism, bilateral ptosis, microphthalmos, megalocornea, glaucoma, retrolental membrane, macular coloboma, optic hypoplasia, ${ }^{2}$ and bilateral 
Table 1. Comparison of the systemic and ocular features of this patient with those of other reports.

\begin{tabular}{|c|c|c|c|}
\hline Features & $\begin{array}{l}\text { Thompson and Pembre, } \\
1985^{4}\end{array}$ & $\begin{array}{l}\text { Majewski and Goecke, } \\
1982^{2}\end{array}$ & $\begin{array}{l}\text { This patient, } \\
2011\end{array}$ \\
\hline Intrauterine growth retardation with proportionate trunk to leg length & $3 / 3$ & $17 / 17$ & Present \\
\hline Short stature (height - 3 SD) & $3 / 3$ & $16 / 17$ & Present \\
\hline Microcephaly and mental retardation & $3 / 3$ & $17 / 17$ & Present \\
\hline \multicolumn{4}{|l|}{ Facial features } \\
\hline Micrognathia and large nose & $3 / 3$ & $17 / 17$ & Present \\
\hline Receding forehead & $3 / 3$ & $17 / 17$ & Present \\
\hline Small palpebral fissures & $3 / 3$ & NR & Present \\
\hline Telecanthus & $3 / 3$ & NR & Present \\
\hline Bulging eyes & $2 / 3$ & $10 / 16$ & Absent \\
\hline Antimongoloid slant & None & $7 / 11$ & Present \\
\hline Cataract & NR & NR & Present \\
\hline High arched palate & $1 / 3$ & $4 / 10$ & Absent \\
\hline Clefting & $1 / 3$ & $3 / 17$ & Absent \\
\hline Small ears & $3 / 3$ & NR & Present \\
\hline Lobeless ears & $3 / 3$ & 10/12 (dysplastic) & Absent \\
\hline Crowded and maloccluded teeth & $3 / 3$ & NR & $?$ \\
\hline \multicolumn{4}{|l|}{ Skeleton } \\
\hline Hand abnormalities & $3 / 3$ & 8/8 clinodactyly V & Present \\
\hline Feet abnormalities & $3 / 3$ & $\begin{array}{l}\text { Gap between first and second } \\
\text { toes, hallux valgus }\end{array}$ & Present \\
\hline Dislocated heads of radii & $3 / 3$ & $3 / 6$ & Absent \\
\hline Hips: fixed flexion & $3 / 3$ & $5 / 9$ & Absent \\
\hline Hips: congenital dislocation & None & None & Absent \\
\hline Knees: fixed flexion & $3 / 3$ & NR & Absent \\
\hline Cryptorchidism & None & $3 / 4$ & Absent \\
\hline Clitoromegaly & None & $3 / 7$ & Absent \\
\hline
\end{tabular}

Abbreviation: $\mathrm{NR}=$ not reported.

Figure 4. Pedigree chart showing the position of the patient and her maternal great-aunt.

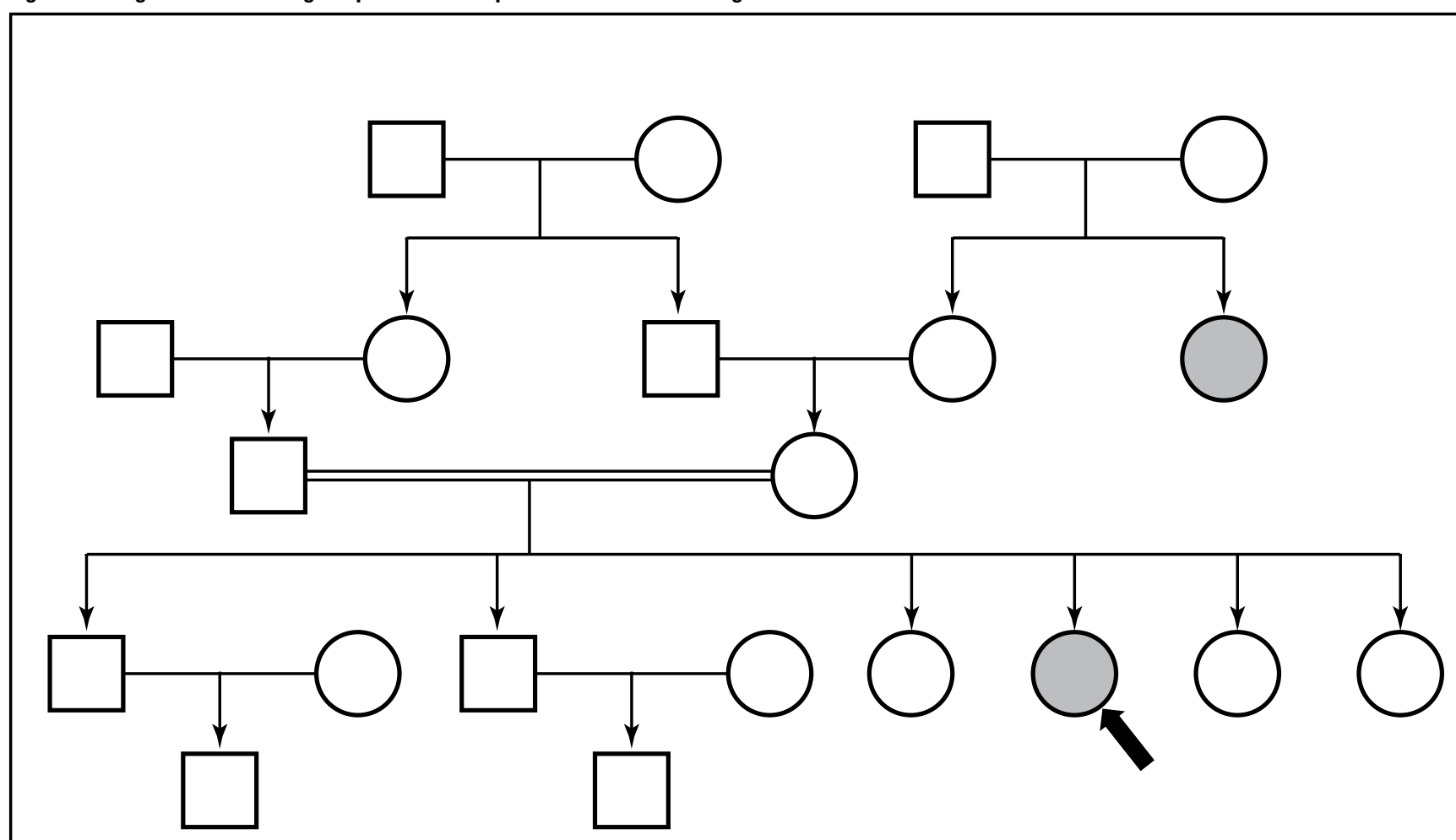


pigmentary retinopathy. ${ }^{3}$ However, this patient had no systemic associations.

A recent patient with diabetes with Seckel syndrome presenting with cataract has been reported. ${ }^{8}$ However, the cataract may be presumed to be due to hyperglycaemia, which is a welldocumented cause of cataract. Cataract in isolation has not yet been associated with Seckel syndrome, but this patient suggests the possibility of an association for these conditions.

\section{References}

1. Seckel HP. Bird-headed dwarfs: studies in developmental anthropology including human proportions. Springfield: Charles C Thomas; 1960.

2. Majewski F, Goecke T. Studies of microcephalic primordial dwarfism I: approach to a delineation of the Seckel syndrome. Am J Med Genet. 1982;12:7-21.

3. Guirgis M, Lam B, Howard C. Ocular manifestations of Seckel syndrome. Am J Ophthalmol. 2001;132:596-7.

4. Thompson E, Pembrey M. Seckel syndrome: an overdiagnosed syndrome. J Med Genet. 1985;22:192-201.

5. Goodship J, Gill H, Carter J, Jackson A, Splitt M, Wright M. Autozygosity mapping of a Seckel syndrome locus to chromosome 3q22.1-q24. Am J Hum Genet. 2000;67:498-503.

6. Kilinc MO, Ninis VN, Ugur SA, et al. Is the novel SCKL3 at 14q23 the predominant Seckel locus? Eur J Hum Genet. 2003;11: 851-7.

7. Shanske A, Caride DG, Menasse-Palmer L, Bogdanow A, Marion RW. Central nervous system anomalies in Seckel syndrome: report of a new family and review of the literature. Am J Med Genet. 1997;70:155-8.

8. Reddy S, Starr C. Seckel syndrome and spontaneously dislocated lenses. J Cataract Refract Surg 2007;33:910-2. 